\title{
Role of Pattern Electroretinogram in Early Detection of Glaucoma
}

\author{
Mohamed Abdel-Monem Mahdy, Mohamed Mohamed-Aly Ibrahim, Mohamed Gamal Mostafa \\ Nasar
}

*Department of Ophthalmology, Faculty of Medicine, Al-Azhar University

Corresponding author: Mohamed Gamal Mostafa Nasar, Mobile: 00201099080936, E-Mail: mgamal692255@ gmail.com

\begin{abstract}
Background: glaucoma is the most common cause of irreversible blindness. Primary open angle glaucoma (POAG) is the most commonly diagnosed form. Pattern electroretinogram emerged as a promising tool for diagnosing of early glaucoma. Aim of the work: the present study aimed to assess the role of pattern electroretinogram in differentiating between patients with early glaucoma and normal controls. Methodology: this study included 25 early glaucoma patients and 25 normal controls. They were undergone into careful history taking, complete ophthalmic examination and investigations by using PERG, SD- OCT and perimetry. Results: regarding the comparison we found reduction in amplitude of P50 and N95 between early glaucoma patients and normal controls.
\end{abstract}

Keywords- PERG, POAG, SAP

\section{Introduction:}

Glaucoma is a group of optic neuropathies characterized by progressive degeneration of retinal ganglion cells. These are central nervous system neurons that have their cell bodies in the inner retina and axons in the optic nerve. Degeneration of these nerves results in cupping, a characteristic appearance of the optic disc and visual loss ${ }^{(1)}$. Glaucoma affects more than 70 million people worldwide with approximately $10 \%$ being bilaterally blind ${ }^{(2)}$ making it the leading cause of irreversible blindness in the world. Glaucoma can remain asymptomatic until it is severe; resulting in a high likelihood that the number of affected individuals is much higher than the number known to have it ${ }^{(3)}$. Primary open angle glaucoma is the most common type of glaucoma which is considered chronic optic progressive neuropathy accompanied by characterstic cupping, atrophy of optic disc, visual field loss, open angle and no obvious systemic or ocular disease ${ }^{(\mathbf{4})}$. Various population-based epidemiological studies have reported that more than $50 \%$ of glaucoma cases remain undiagnosed, even in the developed countries $^{(\boldsymbol{)}}$. Detection of glaucoma at its earliest stage is a major goal for clinician and researcher. Standard achromatic perimetry (SAP) is integral tool for early recognition of visual field loss. Among several limitations of standard achromatic perimetry (SAP), is the subjective nature of the test. This provoked the interest of researcher to look for alternatives, objective information provided by electrophysiological responses, especially those evoked by pattern stimulation (6).Improved strategies for achieving earlier and more accurate diagnosis of glaucoma will facilitate the prompt implementation of effective treatment options, and subsequently will minimize the anticipated rising burden of the disease in the near future ${ }^{(7)}$.

\section{Aim of the work}

This study aimed to assess the ability of Pattern Electroretinogram (PERG) to differentiate between patient with early primary open angle glaucoma (POAG) and normal control patient.

\section{Patients and methods}

This study was carried out on patients attending the outpatient clinic of Damnhour Opthalmology Hospital during the period from January 2018 to September 2018. The study was approved by the Ethics Board of Al-Azhar University.

A total of 50 patients (100 eyes) were included in this study: 25 early glaucoma patients (15 men and 10 women; mean \pm SD age 43,8 \pm 4 years) and 25 age matched normal controls (16 men and 9 women; mean \pm SD age $44,9 \pm 3,6$ years). All patients underwent full opthalmic examination included visual acuity testing, slit lamp biomicroscopy, gonioscopy, IOP measurement, Oct, perimetry and perg. 


\section{Perimetry:-}

Standard achromatic perimetry (SAP) was performed by using Octopus Field Analyser 900 (HAAG - STREIT Co., USA). Patients were tested with undilated pupils using G Standard white /white /Dynamic programe. Optimal lens correction was used and the fellow eye was occluded with eye patch. Patients had performed field tests on two separate occasions and had demonstrated reproducible field results.

\section{Optical coherence tomography:-}

OCT was performed using Nidek 3D OCT RS-3000 Advance 2 (Nidek corporation, Japan). The scan Protocol was the fast one. Two maculas centered and two $\mathrm{ONH}$ centered scan were obtained. OCT volumes were acquired $(2 \times 2$ volumes per patients). Each OCT volume was 200 $\times 200 \times 1024$ voxels, corresponding to a dimension of $6 \times 6 \times 2 \mathrm{~mm}$. Only patients with acceptable quality of both macular and peripapillary OCT images (with signal strength $\geq 50$ ) were included in the study. The mean RGC thickness (Software defined region bound by the presumed internal limiting membrane and the inner plexiform layer) and RNFL thickness (Software-defined region bound by anterior and posterior RNFL borders) were estimated from OCT volumes. The regional RGC thickness for all A-scans in a grid region and similarly the mean RNFL thickness were measured. Images with eye movements during scans, poor centration, poor focus, or high noise were excluded.

\section{Pattern electroretinogram (PERG):-}

Pattern electroretinogram was performed by using RETI Port 21 (Electrophysiological Diagnostic System, Roland Consult; Brandenburg, Germany). PERG was undertaken according to the standards of the International Society for Clinical Electrophysiology of Vision (ISCEV). PERG was simultaneously recorded from both eyes according to a paradigm optimized for glaucoma detection. Responses were recorded using a Dawson-TrickLitzkow thread electrode, which was positioned on the inferior cornea along the lid margin and fixed temporarily. Gold cup reference and surface electrodes were applied to the participant's temple and forehead, respectively. Stimuli were checksmodulated in counter phase and electronically generated on high-resolution T-V stimuli (contrast: $98 \%$, mean luminance: $80 \mathrm{~cd} / \mathrm{m} 2$, field size: $31^{\circ}$ width $\times 24$ height, resolution: $1024 \times 768$ ). The Roland equipment provides LED stimulator to produce the stimulus pattern with homogenous luminance. The pattern reversal needs exchanging between the black and white checks on the checker board, and the numbers of black and white checks should be equal on the screen. Pattern check size was $0.48 \mathrm{~min}$, modulating at a rate of three reversals per second. Patients fixated at the center of the stimulated field placed at a viewing distance of $30 \mathrm{~cm}$ with natural pupils (they did not receive dilating drops). The patients wore full refractive correction for test distance and were allowed to blink freely. Responses were amplified (100 000x), band pass filtered $(1-30 \mathrm{~Hz})$, sampled at $2 \mathrm{kHz}$, and averaged with automated artifact rejection. Two replications were obtained for each record to verify reproducibility. Peak-to-peak amplitude ( $\mu v)$ and implicit time (ms) were measured.

\section{Statistical analysis of the data:-}

Data were fed to the computer using IBM SPSS software package version 20.0.

Qualitative data were described using number and percent. Comparison between different groups regarding categorical variables was tested by using Chi-square test. Quantitative data were described by using mean and standard deviation for normally distributed data, while abnormally distributed data were expressed by using median, minimum and maximum. For normally distributed data, comparison between the two independent population was done by using independent $\mathrm{t}$-test while more than two population were analyzed F-test (ANOVA) to be used. Significance test results were quoted as two-tailed probabilities. Significance of the obtained results was judged at the 5\% level. Chi-Square test: It tests the association between qualitative nominal variables; it was performed mainly on frequencies. It determines whether the observed frequencies differ significantly from the expected frequencies.

\section{Results \\ As regard age and sex among the studied groups there was no significant correlation $(\mathrm{P}>0,05)$ between early glaucoma group and normal control group as shown in table 1.}

Table 1: comparison between the two studied groups regarding demographic data Group I Glaucoma cases Group II Normal Control group P 
Mohamed Mahdy et al.

\begin{tabular}{|c|c|c|c|c|}
\hline Age & Range & $40-55$ & $40-50$ & 0.153 N.S. \\
& Mean \pm SD & $43.8 \pm 4.00$ & $44.92 \pm 3.64$ & \\
\hline Sex & Male & $15(60.0 \%)$ & $16(64.0 \%)$ & 0.388 N.S. \\
& Female & $10(40.0 \%)$ & $9(36.0 \%)$ & \\
\hline
\end{tabular}

N.S.: not significant

As regard mean defect of visual field among the studied groups there was a significant correlation $(\mathrm{P}<0,001)$ between early glaucoma group and normal control group as shown in table 2.

Table 2: comparison between the two studied groups regarding MD

\begin{tabular}{|c|c|c|c|}
\multicolumn{1}{c}{ MD } & $\begin{array}{c}\text { Group I } \\
\text { Glaucoma cases }\end{array}$ & $\begin{array}{c}\text { Group II Normal } \\
\text { Control group }\end{array}$ & P \\
\hline Range & $2-6$ & $0-2$ & $0.0001^{*}$ \\
Mean \pm SD & $3.93 \pm 1.34$ & $1.16 \pm 0.90$ & \\
\hline
\end{tabular}

* Significant at level 0.05

As regard OCT nerve fiber layer thickness among the studied groups there was a significant correlation $(\mathrm{P}<0,001)$ between early glaucoma group and normal control group as shown in table 3 .

Table 3: comparison between the two studied groups regarding OCT nerve fiber layer thickness

\begin{tabular}{|c|c|c|c|c|}
\multicolumn{2}{|c|}{ OCT Nerve fiber layer thickness } & \multicolumn{1}{c|}{$\begin{array}{c}\text { Group I } \\
\text { Glaucoma cases }\end{array}$} & \multicolumn{1}{c|}{$\begin{array}{c}\text { Group II } \\
\text { Normal Control group }\end{array}$} \\
\hline Superior & Range & $90-114$ & $110-133$ & $0.0001^{*}$ \\
& Mean \pm SD & $103.00 \pm 6.75$ & $120.36 \pm 7.65$ & \\
\hline Inferior & Range & $85-105$ & $122-135$ & $0.0001^{*}$ \\
& Mean \pm SD & $94.48 \pm 7.07$ & $128.40 \pm 4.32$ & \\
\hline Nasal & Range & $63-82$ & $80-95$ & $0.0001^{*}$ \\
& Mean \pm SD & $73.72 \pm 4.97$ & $85.32 \pm 4.68$ & \\
\hline Temporal & Range & $51-72$ & $58-84$ & $0.0001^{*}$ \\
& Mean $\pm S D$ & $61.04 \pm 6.77$ & $72.04 \pm 8.09$ & \\
\hline Average & Range & $77.75-90$ & $95.5-108$ & $0.0001^{*}$ \\
& Mean $\pm S D$ & $83.06 \pm 3.66$ & $101.53 \pm 3.58$ & \\
\hline
\end{tabular}

* Significant at level 0.05

As regard macular ganglion cell layer thickness among the studied groups there was a significant correlation $(\mathrm{P}<0,001)$ between early glaucoma group and normal control group as shown in table 4.

Table 4: comparison between the two studied groups regarding macular ganglion cell layer thickness

\begin{tabular}{|c|c|c|c|c|}
\hline \multicolumn{2}{|c|}{$\begin{array}{c}\text { Macular ganglion cell } \\
\text { layer thickness }\end{array}$} & \multirow[t]{2}{*}{$\begin{array}{c}\text { Group I } \\
\text { Glaucoma cases } \\
\end{array}$} & \multirow[t]{2}{*}{$\begin{array}{c}\text { Group II } \\
\text { Normal Control group } \\
\end{array}$} & \multirow[t]{2}{*}{$\mathrm{P}$} \\
\hline I. RGC COMPLEX & & & & \\
\hline Superior & $\begin{array}{c}\text { Range } \\
\text { Mean } \pm \text { SD }\end{array}$ & $\begin{array}{c}41-65 \\
54.68 \pm 7.81 \\
\end{array}$ & $\begin{array}{c}50-75 \\
62.76 \pm 7.79 \\
\end{array}$ & $0.0003^{*}$ \\
\hline Inferior & $\begin{array}{c}\text { Range } \\
\text { Mean } \pm \text { SD }\end{array}$ & $\begin{array}{c}41-65 \\
53.04 \pm 6.60\end{array}$ & $\begin{array}{c}51-78 \\
65.84 \pm 8.29\end{array}$ & $0.0001 *$ \\
\hline Average & $\begin{array}{c}\text { Range } \\
\text { Mean } \pm \text { SD }\end{array}$ & $\begin{array}{c}44-61 \\
53.86 \pm 4.86\end{array}$ & $\begin{array}{c}55.5-75.5 \\
64.30 \pm 5.70\end{array}$ & $0.0001^{*}$ \\
\hline II. RNFL & & & & \\
\hline Superior & $\begin{array}{c}\text { Range } \\
\text { Mean } \pm \text { SD }\end{array}$ & $\begin{array}{c}20-30 \\
25.20 \pm 3.07\end{array}$ & $\begin{array}{c}28-43 \\
35.84 \pm 4.33\end{array}$ & $0.0001^{*}$ \\
\hline Inferior & $\begin{array}{c}\text { Range } \\
\text { Mean } \pm \text { SD }\end{array}$ & $\begin{array}{c}23-32 \\
27.28 \pm 2.78\end{array}$ & $\begin{array}{c}28-48 \\
39.00 \pm 6.79\end{array}$ & $0.0001^{*}$ \\
\hline Average & $\begin{array}{c}\text { Range } \\
\text { Mean } \pm \text { SD }\end{array}$ & $\begin{array}{c}22.5-29 \\
26.24 \pm 2.05\end{array}$ & $\begin{array}{c}29.5-45 \\
37.42 \pm 4.62\end{array}$ & $0.0001^{*}$ \\
\hline
\end{tabular}

* Significant at level 0.05

As regard P50 and N95 amplitude of PERG among the studied groups there was a significant correlation $(\mathrm{P}<0,001)$ between early glaucoma group and normal control group as shown in table 5 . 
Table 5: comparison between the two studied groups regarding P50 AND N95

\begin{tabular}{|c|c|c|c|c|}
\multicolumn{2}{c}{} & \multicolumn{1}{c}{ Group I } \\
Glaucoma cases & Normal Control group & P \\
\hline P50 & Range & $1.6-4.4$ & $4-7.3$ & $0.0001^{*}$ \\
& Mean \pm SD & $3.01 \pm 0.86$ & $5.60 \pm 1.13$ & $0.0001^{*}$ \\
\hline N95 & Range & $2.51-5.30$ & $5.20-8.63$ & \\
& Mean \pm SD & $3.94 \pm 0.84$ & $6.90 \pm 1.13$ & \\
\hline
\end{tabular}

* Significant at level 0.05

\section{DISCUSSION}

Detection of glaucoma at its earliest stage is a major goal for clinician and researcher. Standard achromatic perimetry (SAP) is integral tool for early recognition of visual field loss. Among several limitation of standard achromatic perimetry (SAP), is the subjective nature of the test. This provoked the interest of researcher to look for alternatives, objective information provided by electrophysiological responses, especially those evoked by pattern stimulation (6). The current study included 25 early glaucoma patients and 25 age matched normal control. This study compared the role of pattern electroretinogram (PERG) between early glaucoma patient according to Hoddap. Regarding the comparison there was a significant reduction in amplitude of P50 and N95 between two groups. In the present study we found early glaucoma group had P50 and N95 amplitude ( $3.01 \pm 0.86 \mu \mathrm{v}$, $3.94 \pm 0.84 \mu \mathrm{v}$ respectively), while normal control group had P50 and N95 amplitude $(5.60 \pm 1.13 \mu \mathrm{v}$, $6.90 \pm 1.13 \mu \mathrm{v}$ respectively). This is in harmony with study of Ventura et al. ${ }^{(8)}$ who found that RGC health is necessary for generation of PERG waves and reported inverse correlation between N95 amplitude and the severity of glaucoma such that amplitude reduction was present in 33\% of early glaucoma patients. Similarly, North et al. (9) reported a significant decrease in PERG amplitudes in early glaucoma, compared to the control group. The PERG N95 amplitude was reduced by $30 \%$ in the open-angle glaucoma group. Also, Wolf $\boldsymbol{e t}$ al. ${ }^{(\mathbf{1 0})}$ found significant reduction in Retinal nerve fibre layer (RNFL) thickness and amplitude of pattern electroretinogram (PERG) in early glaucoma patients ${ }^{(\mathbf{1 0})}$.Hood $\boldsymbol{e t}$ al. ${ }^{(11)}$ found a reduction in amplitude of P50 and N95 in the patients with minimal visual field defects. Barbara et al. ${ }^{(12)}$ in their cross sectional study which included 34 patients with early glaucoma and 24 age matched control patients mean P50 amplitude $(\mathrm{IV} \pm \mathrm{SD})$ was $5.2 \pm 1.7$ in the normal control and $3.9 \pm 1.0$ in the early glaucoma group, while mean N95 amplitude $(\mathrm{IV} \pm \mathrm{SD})$ was $7.2 \pm 1.5$ in the normal control group and $5.3 \pm 1.3$ in the early glaucoma group. Also, study of Abdelkader included 70 glaucoma patients and 50 ages matched with the normal controls. Mean amplitude of p50 among normal control group and early glaucoma group were $6 \pm 2$. 6 and $3.1 \pm 1.1$ respectively ${ }^{(13)}$.In the present study we did not detect a correlation between visual field indices and PERG. Also, Hood et al. ${ }^{(11)}$ observed no correlation between PERG N95 amplitude and with MD and they reported that $25 \%$ of patients with abnormal visual field had normal PERG responses. This can be explained by the wide range of amplitude among the normal eyes and the fact that even in advanced glaucoma, PERG was never reduced to zero due to the presence of noise. These conflicting results may be due to the fact that PERG and perimetry were designed to test different aspects of visual function. While, PERG was an objective test and represents a mass response of the central retina, perimetry is a subjective examination based on focal threshold stimulus of the central and peripheral retina.

\section{References}

1. Weinreb RN and Khaw PT (2004): Primary open-angle glaucoma. Lancet, 363:17111720.

2. Quigley HA and Broman AT (2006): The number of people with glaucoma worldwide in 2010 and 2020. Br. J. Ophthalmol., 90:262267.

3. Leite MT, Sakata LM and Medeiros FA (2011): Managing glaucoma in developing countries. Arq. Bras. Oftalmol., 74:83-84.

4. Morgan JE, Uchida $H$ and Caprioli J (2000): Retinal ganglion cell death in experimental glaucoma. Br. J. Opthalml., 84:303-310.

5. Topouzis F, Wilson MR, Harris A et al. (2007): Prevalence of open angle glaucoma in Greece. The Thessaloniki Eye Study. Am. J. Ophthalmol., 19:144:147. 
6. Holder GE (2001): Pattern electroretinography (PERG) and an integrated approach to visual diagnosis. Prog. Retin. Eye. Res., 20:531-561.

7. Topouzis F and Anastasopoulos E (2007): Increasing Prevalence of Myopia in Europe and the Impact of Education. Ophthalmology, 122(7):1489-1497.

8. Ventura LM, Sorokac N, De Los Santos R et al. (2006): The relationship between retinal ganglion cell function and retinal nerve fiber thickness in early glaucoma. Invest. Ophthalmol. Vis. Sci., 47:3904-3911.

9. North RV, Jones AL, Drasdo N et al. (2010): Electrophysiological evidence of early functional damage in glaucoma and ocular hypertension. Invest. Ophthalmol., 51:12161222.
10. Wolff K, Treumer F, Jochens A et al. (2012): Screening for glaucoma by blue light-pattern ERG and OCT - are the methods comparable. Klin. Monbl. Augenheilkd., 229:1215-1222.

11. Hood DC, Xu L, Greenstein VC et al. (2005): The pattern electroretinogram in glaucoma patients with confirmed visual field deficits. Invest. Ophthalmol. Vis. Sci., 46:2411-2418.

12. Cvenkel B, Sustar $M$ and Perovšek D (2017): Ganglion cell loss in early glaucoma, as assessed by photopic negative response, pattern electroretinogram, and spectral-domain optical coherence tomography. Doc. Ophthalmol., 135(1):17-28.

13. Abdelkader M (2016): Functional and anatomical assessment of retinal ganglion cells in glaucoma. Delta. J. Ophthalmol., 17:65-72. 